\title{
Hypotension Associated with MTS is Aggravated by Early Activation of TEA During Open Esophagectomy
}

This article was published in the following Dove Press journal: Local and Regional Anesthesia

\author{
Rune B Strandby' \\ Rikard Ambrus' \\ Linea L Ring' \\ Nikolaj Nerup' \\ Niels H Secher ${ }^{2}$ \\ Jens $\mathrm{P}$ Goetze ${ }^{3}$ \\ Michael P Achiam (D) \\ Lars B Svendsen (D) \\ 'Department of Surgical \\ Gastroenterology, Rigshospitalet, \\ Institute for Clinical Medicine, University \\ of Copenhagen, Copenhagen, Denmark; \\ ${ }^{2}$ Department of Anesthesia, \\ Rigshospitalet, Institute for Clinical \\ Medicine, University of Copenhagen, \\ Copenhagen, Denmark; ${ }^{3}$ Department of \\ Clinical Biochemistry, Rigshospitalet, \\ Institute for Clinical Medicine, University \\ of Copenhagen, Copenhagen, Denmark
}

Correspondence: Rune B Strandby Department of Surgical Gastroenterology, Institute for Clinical Medicine, University of Copenhagen, Rigshospitalet, 2I22, Inge Lehmanns Vej 7, Copenhagen, DK-2100, Denmark

Tel +452245 I331

Email runestrandby@hotmail.com
Objective: A mesenteric traction syndrome (MTS) is elicited by prostacyclin $\left(\mathrm{PGI}_{2}\right)$ induced vasodilation and identified by facial flushing, tachycardia, and hypotension during abdominal surgery. We evaluated whether thoracic epidural anesthesia (TEA) influences the incidence of MTS.

Design: Randomized, blinded controlled trial.

Setting: Single-center university hospital.

Participants: Fifty patients undergoing open esophagectomy.

Interventions: Patients were randomized to either early (EA, after induction of general anesthesia) or late activation of TEA (LA, after re-established gastric continuity). Plasma 6-keto-PGF ${ }_{1 \alpha}$, a stable metabolite of PGI $_{2}$ and interleukine-6 (IL6) were measured in plasma during surgery along with hemodynamic variables and MTS graded according to facial flushing together with plasma C-reactive protein on the third post-operative day.

Results: Forty-five patients met the inclusion criteria. Development of MTS tended to be more prevalent with EA $(n=13 / 25[52 \%])$ than with LA TEA $(n=5 / 20$ [25\%], $p=0.08)$. For patients who developed MTS, there was a transient increase in plasma 6-keto- $\mathrm{PGF}_{1 \alpha}$ by 15 min of surgery and plasma IL6 $(\mathrm{p}<0.001)$ as $\mathrm{C}$-reactive protein $(\mathrm{P}<0.009)$ increased. EA TEA influenced the amount of phenylephrine needed to maintain mean arterial pressure $>60$ $\mathrm{mmHg}$ in patients who developed MTS $(0.16$ [0.016-0.019] $\mathrm{mg} / \mathrm{min}$ vs MTS and LA TEA 0.000 [0.000-0.005] $\mathrm{mg} / \mathrm{min}, \mathrm{p}<0.001)$.

Conclusion: The incidence of MTS is not prevented by TEA in patients undergoing open esophagectomy. On the contrary, the risk of hypotension is increased in patients exposed to TEA during surgery, and the results suggest that it is advantageous to delay activation of TEA. Also, MTS seems to be associated with a systemic inflammatory response, maybe explaining the aggravated post-operative outcome.

Keywords: mesenteric traction syndrome, esophagectomy, epidural anesthesia

\section{Introduction}

A mesenteric traction syndrome (MTS) manifests during abdominal surgery with a frequency of up to $80 \%$ for open procedures. ${ }^{1-3}$ MTS is defined by a triad of hypotension, tachycardia, and facial flushing most often elicited within 20 min after skin incision. ${ }^{2,4}$ The hypotensive episode is usually moderate ${ }^{5,6}$ lasting for only about $30 \mathrm{~min}$ after facial flushing ${ }^{7}$ but may be severe and even unresponsive to

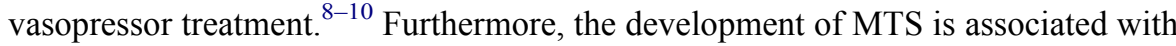
severe postoperative complications after open esophagectomy ${ }^{3}$ as with other types 
of major abdominal surgery. ${ }^{11}$ The pathophysiological link between the development of MTS and complication rate may include hypotension ${ }^{12,13}$ and induction of a systemic inflammatory response syndrome. ${ }^{14,15}$

The cardiovascular response to MTS involves reduced peripheral vascular resistance facilitated by prostacyclin $\left(\mathrm{PGI}_{2}\right)$ released to plasma ${ }^{5,14}$ triggered by manipulation of vascular endothelial cells in the mesentery and small intestine $^{16}$ to maintain splanchnic blood flow. ${ }^{17,18}$ For example, plasma $\mathrm{PGI}_{2}$ increases in response to splanchnic ischemia and withdrawal of blood in animals, ${ }^{19-21}$ and with MTS the $\mathrm{PGI}_{2}$ response seems to elicit hemodynamic instability. Also, the release of plasma $\mathrm{PGI}_{2}$ is stimulated by factors that influence splanchnic vessel tone and blood flow; eg the incidence of MTS increases when remifentanil (a vasodilative agent) rather than fentanyl is administered during surgery. ${ }^{4}$ Whether MTS also involves a neural component is not known but can be evaluated because major abdominal surgery is performed often under cover of neuraxial anesthesia.

Thoracic epidural anesthesia (TEA) is provided for open major abdominal surgery and inhibits sympathetic drive to the splanchnic vessels, affecting both blood pressure and the splanchnic blood flow. ${ }^{22,23}$ Here, we evaluated whether TEA influences the incidence of MTS during open esophagectomy as determined by hemodynamic variables and facial flushing. TEA was activated either early (EA), ie after induction of general anesthesia before abdominal incision, or late (LA), ie after the gastroesophageal continuity was re-established by the end of surgery. Furthermore, C-reactive protein (CRP) and interleukine-6 (IL6) were examined to evaluate a link to a systemic inflammatory response.

\section{Patients and Methods}

This study was a blinded, randomized controlled trial conducted between 2014-2016. ${ }^{24}$ The study was registered at the European Medicines Agency (EudraCT 2014-002036-14) as approved by the Scientific Ethical Committee, The Capital Region, Denmark (H-2-2013101 by July 14th 2014) and the Danish Health and Medicines Authority (No. 2014060551 by August 8th 2014), and was monitored by the Good Clinical Practice unit at Copenhagen University Hospital (No. 2014-4661). Verbal and written consent was obtained from the patients before enrolment. The primary outcome was the influence of EA vs LA TEA on the incidence of facial flushing to indicate MTS. Secondary outcomes were hemodynamic variables, plasma 6-keto$\mathrm{PGF}_{1 \alpha}$, a stable metabolite of $\mathrm{PGI}_{2}$, and markers of systemic inflammation in response to surgery: CRP and IL6.

\section{Inclusion and Exclusion Criteria}

Adults with a biopsy verified gastroesophageal junction adenocarcinoma scheduled for open Ivor-Lewis esophagectomy $^{25}$ were included. Moreover, access to flushing data, hemodynamic variables, and blood samples obtained during surgery were required for inclusion, but patients were excluded if TEA was contraindicated (allergy to local anesthetics, skin infection, and/or coagulation deficits) or disseminated disease was identified during surgery.

\section{Randomization and Blinding}

Block-randomization was used (www.random.org) and numbered envelopes padded by non-transparent paper ensured blinded allocation of patients to either EA or LA TEA. The randomization sequence was concealed from the principal investigator by ensuring entrance to the operating room only after induction of anesthesia and he left the room (for about $10 \mathrm{~min}$ ) during re-establishment of gastric continuity.

\section{Anesthesia}

An epidural catheter (Epidural Minipack System 1, Smiths Medical, Hranice, CZ) was placed at the 7-8th or 8-9th thoracic intervertebral space by the loss of resistance technique with intravascular placement ruled out by lack of response to administration of $4 \mathrm{~mL}$ lidocaine/adrenaline (20 $\mathrm{mg} / 5 \mu \mathrm{g} / \mathrm{mL}$ ). Initiation of TEA was by a bolus injection of $4 \mathrm{~mL}$ bupivacaine $(5 \mathrm{mg} / \mathrm{mL})$ followed by administration of bupivacaine/morphine $(2.5 \mathrm{mg} / 50 \mu \mathrm{g} / \mathrm{mL})$ at $4 \mathrm{~mL} / \mathrm{h}$.

Induction and maintenance of general anesthesia were with propofol (induction: $2.0 \mathrm{mg} / \mathrm{kg}$; maintenance $5-10 \mathrm{mg} / \mathrm{kg} / \mathrm{h}$ ), remifentanil (induction: $0.5 \mu \mathrm{g} / \mathrm{kg}$; maintenance: $1.75-2.25 \mathrm{mg} / \mathrm{h}$ ), and cisatracurium guided by "train of four" monitoring to facilitate the placement of a double-lumen endobronchial tube. Also, a catheter was placed in the radial artery of the non-dominant arm and a central venous line was used for the administration of blood products and fluid.

Lactated Ringer's solution $(3 \mathrm{~mL} / \mathrm{kg} / \mathrm{h})$ was administered and human albumin 5\% replaced the blood loss 1:1. In addition, ephedrine $(0.1-0.2 \mathrm{~mL}[50 \mathrm{mg} / \mathrm{mL}])$ and/or 
phenylephrine $(0.1-0.2 \mathrm{~mL}[1 \mathrm{mg} / \mathrm{mL}])$ were administered if mean arterial pressure (MAP) fell below $60 \mathrm{mmHg}$.

\section{Facial Flushing}

MTS was graded according to the intraoperative facial flushing score as evaluated by the principal investigator within the first hour of surgery. ${ }^{11,26}$ The nurse anesthesiologist confirmed the evaluation and in case of disagreement, the assessment was discussed among them. Development of severe MTS was defined as flushing including the face, neck, shoulders, and upper torso. ${ }^{4}$ Moderate MTS was flushing of the cheeks or forehead, and non-MTS as the absence of flushing. For analysis, the patients were allocated into two groups, ie MTS vs moderate or non-MTS, because non-MTS and moderate MTS are difficult to distinguish. ${ }^{26}$

\section{Plasma Variables}

Plasma 6-keto-PGF ${ }_{1 \alpha}$, a stable metabolite of $\mathrm{PGI}_{2}$, was measured from arterial blood collected after induction of anesthesia, after laparotomy, by $15 \mathrm{~min}$ of surgery, and after mobilization of the stomach. Furthermore, plasma for IL6 was obtained at baseline, by the end of surgery, and 18 $\mathrm{h}$ postoperatively and for C-reactive protein on postoperative day 3 .

EDTA tubes were used for the blood samples and centrifuged at $3.000 \mathrm{rpm}$ for $10 \mathrm{~min}$ at $4^{\circ} \mathrm{C}$ and the plasma stored at $-80^{\circ} \mathrm{C}$ until analysis. Plasma 6-keto-PGF ${ }_{1 \alpha}$ was determined by an Enzyme-linked Immunosorbent Assay (ELISA) kit (ADI-900-00, Enzo Life Science, Lörrach, DE). Plasma IL6 was measured by a Bio-plex Pro Human Chemokine Assays (Bio-Rad, CA, USA) and CRP by a particle-enhanced turbidimetric immunoassay (Roche Diagnostics, Basel, CH).

\section{Hemodynamic Variables}

Together with the blood-samples hemodynamic variables were obtained by pulse wave analysis (Nexfin, BMEYE $\mathrm{BV}$, Amsterdam, NL) attained from the radial artery including MAP, heart rate (HR), cardiac output (CO), and systemic vascular resistance (SVR) recorded as $30 \mathrm{~s}$ averages.

\section{Statistics}

The statistical analysis was by SPSS (IBM SPSS Statistics for Windows, Version 22.0. Armonk, NY, USA) and graphs constructed by GraphPad Prism Software (Version 7.0, San Diego, CA, USA). Data were tested for normality using the Shapiro-Wilk test and for data not normally distributed logarithmic transformation was applied. For measurements within-groups during surgery, variables were tested by oneway ANOVA with repeated measures and Bonferroni correction. To test for differences between groups at a single time point, a Student's $t$-test was applied. To evaluate predictors for developing MTS, a univariate analysis was conducted using a $X^{2}$-test, Fisher's exact test, or linear regression analysis as appropriate, and associations with a p-value $<0.20$ were explored in multivariate analyses. MTS is reported in $68 \%$ (open) and 20\% (robot-assisted esophagectomy) of patients with EA TEA (open) and LA TEA (robot-assisted), respectively. ${ }^{3}$ A power calculation indicated that 16 patients were required in each group to detect a difference of $48 \%$ in the incidence of MTS between patients randomized to EA and LA TEA (beta: 0.80 and alpha: 0.05). To account for dropouts, 25 patients were included in each group. Data represent mean $\pm \mathrm{SD}$ and a $\mathrm{p}$-value $<0.05$ was considered statistically significant.

\section{Results}

Fifty patients met the inclusion criteria, but five patients were excluded (Figure 1). Hence, 25 (EA) and 20 (LA) patients were randomized to TEA. The baseline characteristics were balanced between groups (Table 1).

\section{Facial Flushing}

Within the first hour of surgery $13 / 25$ (EA, 52\%) and 5/20 (LA, 25\%) patients developed MTS. There was a nonsignificant association between EA TEA and the development of MTS in uni- $(\mathrm{p}=0.078)$ and ordinal regression analysis $(\mathrm{p}=0.071)($ Table 2$)$.

\section{Plasma 6-Keto-PGF ${ }_{1 \alpha}$}

At baseline, plasma 6-keto-PGF ${ }_{1 \alpha}$ was with no explanation lower in patients without MTS as compared with those who manifested MTS ( $\mathrm{p}=0.047$ ) (Table 3). By $15 \mathrm{~min}$ of surgery, plasma 6-keto- $\mathrm{PGF}_{1 \alpha}$ increased in all patients, but became about four times higher in those who developed MTS than in those who did not $(\mathrm{p}<0.001)$.

In patients with EA TEA developing MTS, plasma 6-keto-PGF ${ }_{1 \alpha}$ increased from after laparotomy and to a peak by $15 \mathrm{~min}$ of surgery while in the patients with LA TEA and MTS plasma 6-keto-PGF ${ }_{1 \alpha}$ increased only by 15 min of surgery. However, for the five patients who developed MTS with LA TEA, the increase in plasma 6-keto-PGF ${ }_{1 \alpha}$ reached a similar level by $15 \mathrm{~min}$ as compared with patients developing MTS in the EA group (Figure 2, Table 3). Similarly, by $15 \mathrm{~min}$ of surgery, 


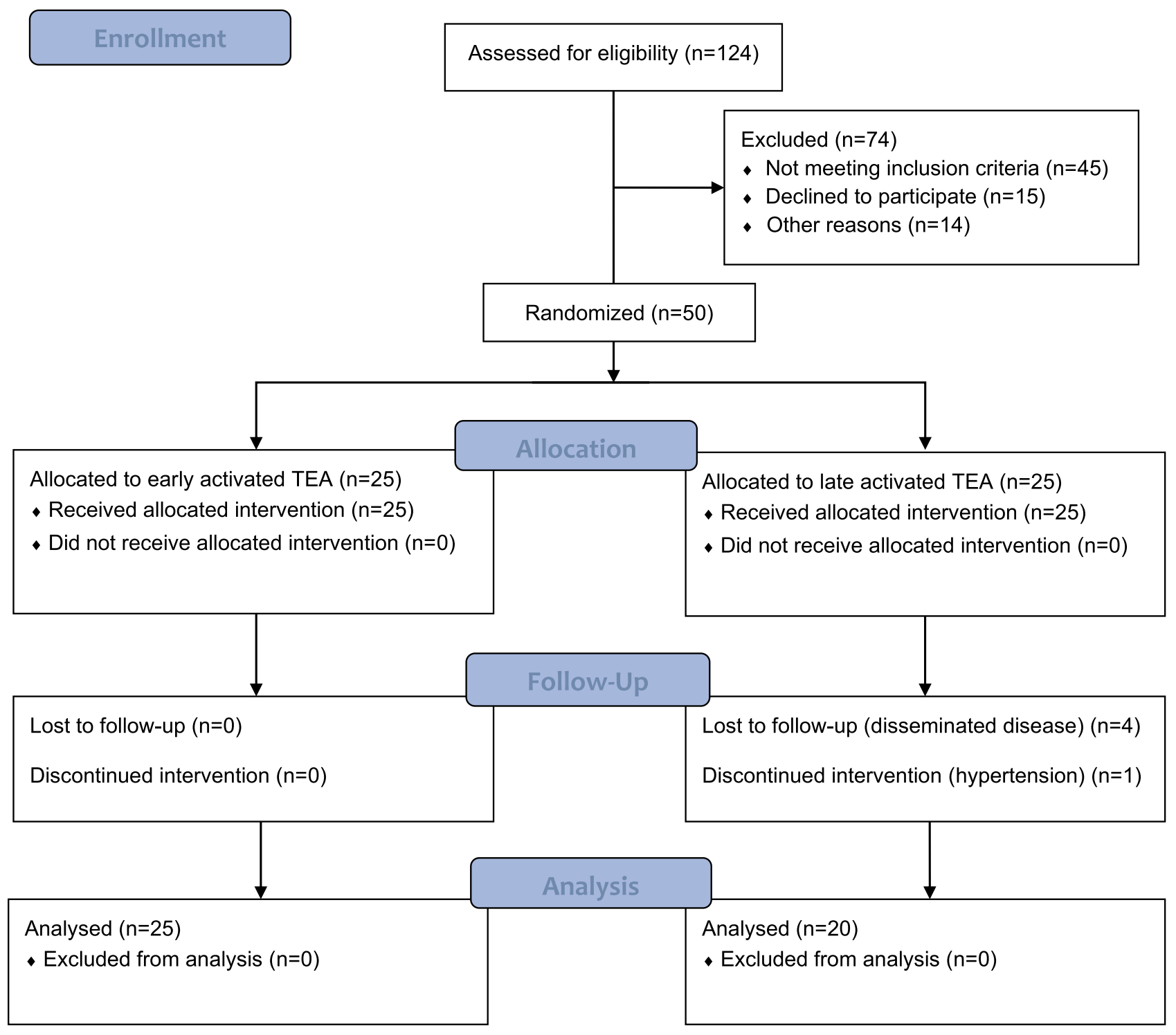

Figure I Consort flow chart.

plasma 6-keto-PGF ${ }_{1 \alpha}$ was not significantly different in non-MTS patients in the two groups $(\mathrm{p}=0.095)$. By the end of the abdominal procedure, ie after mobilization of the stomach approximately $1 \mathrm{~h}$ after skin incision, plasma 6-keto-PGF ${ }_{1 \alpha}$ decreased in patients with MTS (EA: $\mathrm{p}=0.005$ and LA: $\mathrm{p}=0.049$ ) and became similar to that in patients without MTS (Table 3).

\section{Plasma IL6}

By the end of surgery plasma IL6 was higher in patients with MTS than in those who did not develop MTS $(\mathrm{p}=0.008)$ (Table 5). The increase in plasma IL6 was associated with both the development of MTS ( $r=0.320$, $\mathrm{p}=0.034)$ and with EA TEA $(\mathrm{r}=0.425, \mathrm{p}=0.001)$.

\section{C-Reactive Protein}

On the third postoperative day, CRP was higher in patients who developed MTS than in those who did not (161 [107-248] vs 111 [77-154] mg/l, p=0.009). Accordingly, the increase in CRP was associated with the development of MTS ( $r=0.397, p=0.008)$ but not with the timing of TEA $(r=-0.237, p=0.126)$.

\section{Hemodynamic Variables \\ Relation to MTS}

In patients without MTS, SVR decreased by $15 \mathrm{~min}$ of surgery $(p<0.001)$ although HR and MAP remained stable. Also, in patients who developed MTS, SVR decreased by 15 min of surgery at a stable MAP, while HR increased 
Table I Baseline and Intraoperative Characteristics for Patients with Thoracic Epidural Anesthesia (TEA) Activated Either Early or Late During Esophagectomy

\begin{tabular}{|l|l|l|}
\hline & Early TEA & Late TEA \\
\hline Sex, male/female, $\mathrm{n}$ & $20 / 5$ & $16 / 4$ \\
Age, years & $64.1 \pm 7.8$ & $65.1 \pm 7.8$ \\
BMI, kg/m & $27.5 \pm 3.3$ & $27.9 \pm 4.7$ \\
ASA score & $2.2 \pm 0.5$ & $2.2 \pm 0.4$ \\
Length of operation, min & $262 \pm 46$ & $253 \pm 44$ \\
Blood loss, mL & $813 \pm 469$ & $736 \pm 389$ \\
\hline MTS, $\mathrm{n}(\%)$ & & \\
None & $4 / 25(16 \%)$ & $7 / 20(35 \%)$ \\
Moderate & $8 / 25(32 \%)$ & $8 / 20(40 \%)$ \\
Severe & $13 / 25(52 \%)$ & $5 / 20(25 \%)$ \\
\hline
\end{tabular}

Note: Values are means $\pm S D$.

Abbreviations: ASA, American Society of Anesthesiologists; BMI, body mass index; MTS, mesenteric traction syndrome.

Table 2 Uni- and Multivariate Analysis

\begin{tabular}{|c|c|c|c|}
\hline Univariate Analysis & & $\begin{array}{l}\text { Ordinal } \\
\text { Regression }\end{array}$ & \\
\hline Variables & P-value & Odds ratio $(95 \% \mathrm{Cl})$ & P-value \\
\hline Age $\geq 65$ vs $<65$ years & 0.763 & & \\
\hline EA vs LA TEA & 0.078 & I.2(-0.I-2.5) & 0.071 \\
\hline ASA score $>2$ vs $\leq 2$ & 0.445 & & \\
\hline $\mathrm{BMI} \geq 27$ vs $<27 \mathrm{~kg} / \mathrm{h}^{2}$ & 0.767 & & \\
\hline $\begin{array}{l}\text { Vasopressor }>2 \text { vs } \leq 2 \\
\text { boluses after induction } \\
\text { of anesthesia }\end{array}$ & 0.760 & & \\
\hline
\end{tabular}

Notes: Dependent variable: non-MTS vs +MTS. Univariate analysis by $X^{2}$ or Fisher's exact test. Results with a $\mathrm{p}$-value $\leq 0.20$ was included in the ordinal regression model.

Abbreviations: EA and LA, early and late activation of thoracic epidural anesthesia (TEA); ASA, American Society of Anaesthesiologists; BMI, body mass index.

(Table 3). However, for those patients who manifested MTS, a stable MAP (>60 $\mathrm{mmHg}$ ) required administration of more phenylephrine than to those without MTS $(\mathrm{p}=0.029)$ (Table 4).

\section{Relation to TEA}

In patients with EA TEA developing MTS, MAP and CO were significantly lower by $15 \mathrm{~min}$ of surgery than in patients with LA TEA developing MTS. These findings manifested although patients with EA TEA and MTS were administered more phenylephrine to maintain MAP $>60$ mmHg during surgery as compared with those with MTS and LA TEA $(0.016[0.016-0.019]$ vs 0.000 [0.000-0.005] mg/mL, $\mathrm{p}<0.001)$.

\section{Discussion}

This study found MTS in about $40 \%$ of patients going through open esophagectomy and associated with an increase in plasma 6-keto-PGF ${ }_{1 \alpha}$ besides plasma IL6 during surgery and in C-reactive protein on the third post-operative day. A mesenteric traction syndrome is characterized by facial flushing combined with tachycardia and hypotension, but according to local practice, MAP is defended by the administration of ephedrine and/or phenylephrine on the choice of the anesthesiologist if MAP drops to below 60 $\mathrm{mmHg}$. Yet, to maintain a MAP $>60 \mathrm{mmHg}$ required administration of about three times more phenylephrine in the patients who developed MTS, supporting that hypotension is a problem for patients with MTS.

During anesthesia several factors influence MAP. Besides the influence of MTS, general anesthesia influences MAP, ${ }^{27}$ and also epidural anesthesia reduces SVR due to sympathetic blockade. ${ }^{28-31}$ The present study evaluated whether MTS is influenced by TEA, and by comparing patients who were exposed to "early" vs "late" activation of TEA, the incidence of MTS was not statistically different. However, patients with EA TEA developing MTS presented lower blood pressure and $\mathrm{CO}$ by $15 \mathrm{~min}$ of surgery while requiring more vasopressor treatment to maintain $\mathrm{MAP}>60 \mathrm{mmHg}$ as compared with LA TEA patients manifesting MTS. Thus, neuraxial anesthesia did not prevent but rather tended to aggravate flushing and the need to support blood pressure. Considering the relatively high incidence of MTS, timing of TEA seems relevant as prolonged hypotension (MAP $<60$ $\mathrm{mmHg}$ ) during surgery increases the rate of both acute kidney, ${ }^{12}$ and myocardial injury, ${ }^{13}$ and excessive use of vasopressors is associated with increased leakage of gastrointestinal anastomoses. ${ }^{32}$ Furthermore, the development of MTS during surgery is associated with postoperative complications after esophagectomy, ${ }^{3}$ hepatectomy, and pancreaticoduodenectomy ${ }^{11}$ (Dindo-Clavien grade 3-5). ${ }^{33}$ Whether hemodynamic instability explains the association between the development of MTS and severe postoperative complications remains to be elucidated. Yet, to reduce perioperative hypotensive episodes, delayed activation of TEA could be considered.

Patients manifesting MTS had the full response by 15 min of surgery. For these patients, plasma 6-keto-PGF $1 \alpha$ peaked with an approximately four-fold higher plasma concentration as compared with patients who did not develop MTS, mirroring the results from other studies. ${ }^{5,14}$ Yet, the timing of TEA did not influence peak 
Table 3 Prostacyclin and Hemodynamic Changes During Esophagectomy

\begin{tabular}{|c|c|c|c|c|}
\hline & Baseline & After Laparotomy & I5 Min of Surgery & After Mobilization of the Stomach \\
\hline \multicolumn{5}{|c|}{ 6-keto-PGF $\left.\right|_{1 \alpha}(\mathrm{pg} / \mathrm{mL})$} \\
\hline EA -MTS & $166(102-262)$ & $408(25|-| 08 I)$ & $1965(|60|-29 \mid 1)^{b}$ & $1496(963-2846)^{\mathrm{b}}$ \\
\hline LA -MTS & $306(128-474)$ & $385(156-805)$ & $1352(723-2010)^{b}$ & $928(516-1495)^{\mathrm{b}, *}$ \\
\hline $\mathrm{EA}+\mathrm{MTS}$ & & $1574(537-3230)^{\mathrm{b}}$ & $4378(2529-9917)^{\mathrm{b}}$ & $1668(999-2433)^{\mathrm{b}}$ \\
\hline LA +MTS & & $590(460-1206)$ & $5893(5028-6806)^{\mathrm{b}}$ & $|53|(960-2878)^{b}$ \\
\hline \multicolumn{5}{|l|}{ MAP $(\mathrm{mmHg})$} \\
\hline EA -MTS & $73 \pm 15$ & $64 \pm 14$ & $63 \pm 12^{b}$ & $67 \pm 12$ \\
\hline LA -MTS & & $74 \pm 11$ & $75 \pm 14$ & $67 \pm 10$ \\
\hline $\mathrm{EA}+\mathrm{MTS}$ & $71 \pm 15$ & $63 \pm 16$ & $60 \pm 9$ & $65 \pm 8$ \\
\hline$L A+M T S$ & & $87 \pm 10^{*}$ & $84 \pm 15^{*}$ & $68 \pm 9$ \\
\hline \multicolumn{5}{|c|}{ HR (beat/min) } \\
\hline EA -MTS & $63 \pm 14$ & $69 \pm 20$ & $71 \pm 10$ & $68 \pm 13$ \\
\hline LA -MTS & & $59 \pm 9$ & $71 \pm 12^{\mathrm{a}}$ & $70 \pm 9$ \\
\hline $\mathrm{EA}+\mathrm{MTS}$ & $70 \pm 12$ & $62 \pm 10$ & $70 \pm 12^{\mathrm{a}}$ & $64 \pm 9$ \\
\hline$L A+M T S$ & & $69 \pm 9$ & $89 \pm 14^{\mathrm{a}, *}$ & $77 \pm 12^{*}$ \\
\hline \multicolumn{5}{|c|}{ SVR (dyn s/cm $\left.{ }^{5}\right)$} \\
\hline EA -MTS & $1374 \pm 479$ & $1233 \pm 242$ & $943 \pm 234^{\mathrm{a}, \mathrm{b}}$ & $1136 \pm 219^{b}$ \\
\hline LA -MTS & & $1405 \pm 589$ & $1065 \pm 393^{\mathrm{a}, \mathrm{b}}$ & $1117 \pm 497^{b}$ \\
\hline EA + MTS & $1324 \pm 347$ & $1110 \pm 359^{b}$ & $855 \pm 173^{b}$ & $1130 \pm 198$ \\
\hline LA +MTS & & $1437 \pm 367$ & $926 \pm 278^{\mathrm{a}}$ & $|16| \pm 269$ \\
\hline \multicolumn{5}{|l|}{$\mathrm{CO}(1 / \mathrm{min})$} \\
\hline EA -MTS & $4.7 \pm 1.1$ & $4.5 \pm 0.9$ & $5.5 \pm 1.0^{\mathrm{a}, \mathrm{b}}$ & $4.9 \pm 1.1$ \\
\hline LA -MTS & & $4.5 \pm 0.9$ & $5.6 \pm 0.9^{\mathrm{a}, \mathrm{b}}$ & $4.9 \pm 0.8$ \\
\hline$E A+M T S$ & $4.9 \pm 0.8$ & $4.8 \pm \mathrm{I}$ & $5.9 \pm 1.2^{\mathrm{a}, \mathrm{b}}$ & $4.8 \pm 0.8$ \\
\hline$L A+M T S$ & & $5.1 \pm 1.2$ & $7.7 \pm 1.4^{\mathrm{b}, *}$ & $5.0 \pm 0.8$ \\
\hline
\end{tabular}

Notes: Values are means \pm SD or median (IQR). ${ }^{*} p<0.05$, different compared to the between-group value. ${ }^{a} \mathrm{p}<0.05$, different from "after laparotomy" within groups. ${ }^{\mathrm{b}}<0.05$, different from "baseline" within groups.

Abbreviations: EA and LA, early and late activated thoracic epidural anesthesia, respectively; +MTS, mesenteric traction syndrome; -MTS, non or moderate mesenteric traction syndrome; MAP, mean arterial pressure; HR, heart rate; SVR, systemic vascular resistance; CO, cardiac output.

plasma 6-keto-PGF ${ }_{1 \alpha}$ in patients manifesting MTS indicating that the plasma 6-keto-PGF ${ }_{1 \alpha}$ response to MTS was not related to the randomization. Thus, the primary concern for the anesthesiologist when MTS develops concomitantly with EA TEA seems to be hemodynamic instability. Similarly, in 100 patients randomized to remifentanil plus fentanyl vs fentanyl alone for intraoperative analgesia during major abdominal surgery, the incidence of MTS was three-fold higher with remifentanil. ${ }^{4}$ Remifentanil is a $\mu$-opioid agonist and induces vasodilation possibly by suppressing the sympathetic influence on blood vessels as is also the case for TEA. ${ }^{34}$ Furthermore, the study reported similar peak plasma 6-keto-PGF $1 \alpha$ during MTS with both remifentanil and fentanyl and suggest reservation of the use of remifentanil to the last part of the operation to allow for rapid extubation.

Plasma markers of systemic inflammation were high in patients developing MTS, ie higher plasma IL6 by the end of surgery and CRP on postoperative day three which suggests a link between MTS and systemic inflammation response to surgery. Plasma IL6 peaks by the end of surgery, ${ }^{15,35}$ and predicts postoperative complications after major abdominal surgery, ${ }^{15,36}$ while CRP reaches a maximum during the first postoperative days ${ }^{37,38}$ and predicts complications after esophagectomy ${ }^{39}$ and even death after major abdominal surgery. ${ }^{38}$ Yet, the $\mathrm{PGI}_{2}$ 

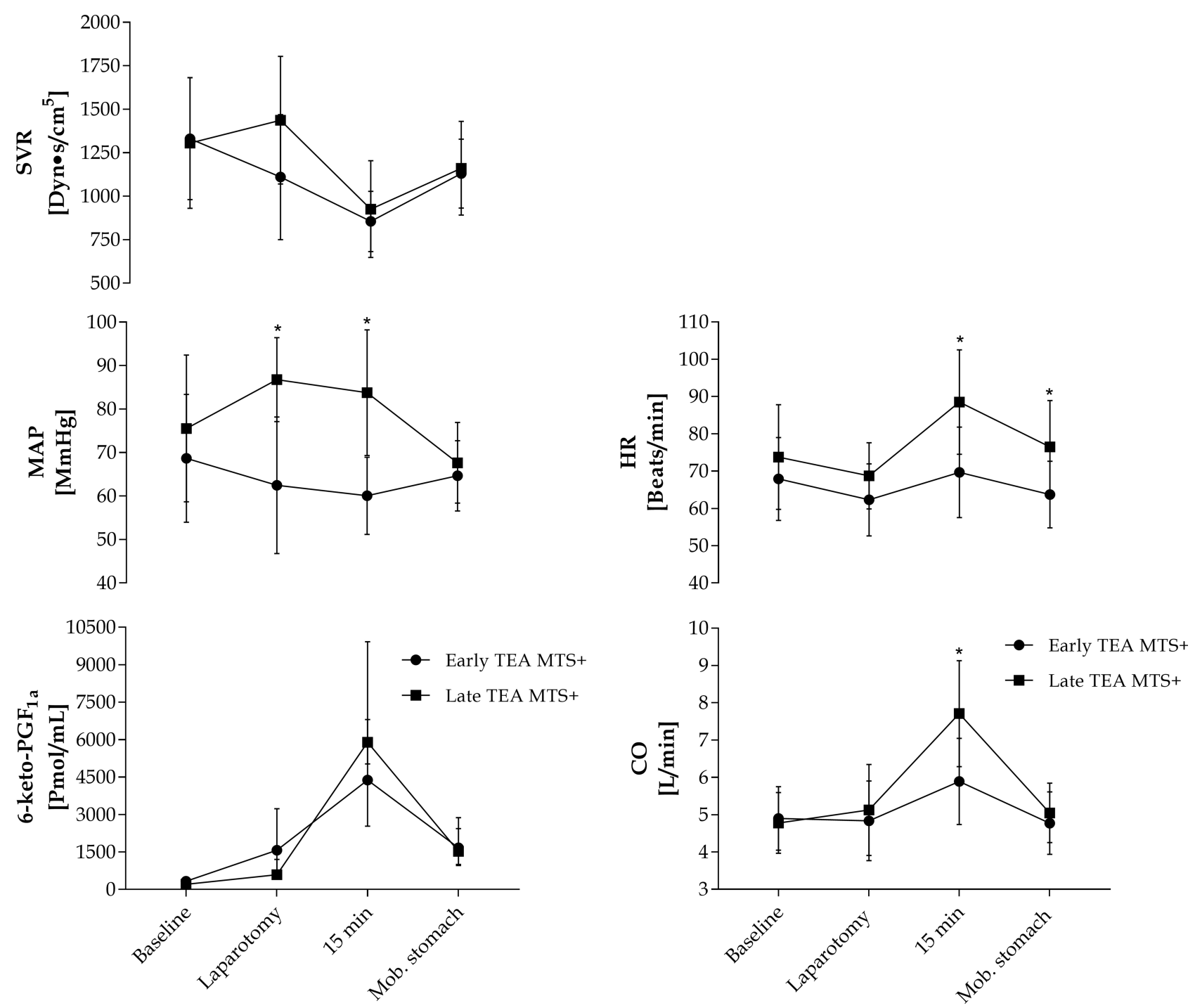

Figure 2 Plasma 6-keto-PGF $\left.\right|_{\alpha \alpha}$ and hemodynamic variables in patients developing MTS Values are mean \pm SD (hemodynamic variables) or median (IQR; plasma 6-keto-

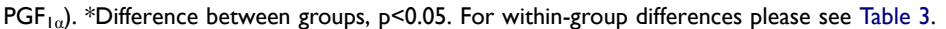

Abbreviations: EA/LA, early and late activation of thoracic epidural anesthesia (TEA); HR, heart rate; CO, cardiac output; MAP, mean arterial pressure; SVR, systemic vascular resistance.

response to MTS is attenuated or abolished by nonsteroidal anti-inflammatory drugs (NSAID), ${ }^{2,5,7}$ and perhaps also by corticosteroids ${ }^{26}$ which is administered often to reduce the inflammatory response to surgery. Accordingly, cardiovascular stability is achieved by NSAID during abdominal surgery, ${ }^{2}$ but at the expense of impaired coagulation and increased risk of anastomotic dehiscence. $^{40,41}$ Moreover, after intentional mesenteric traction in NSAID treated patients, plasma endotoxin increases, and bacterial translocation to mesenteric lymph nodes manifests ${ }^{14}$ may be supporting that $\mathrm{PGI}_{2}$ protects the gut barrier integrity during surgery. ${ }^{42}$
Some study limitations should be considered. Facial flushing was determined visually but an objective determination of facial flushing by measuring skin blood flow is possible. $^{26}$ In one study, severe facial flushing (MTS grade 2) could be distinguished from moderate- (MTS grade 1) and no flushing while no difference in skin blood flow was found when comparing moderate and no flushing. Thus, suggesting that MTS may only be identified with certainty in patients developing severe flushing, and this group of patients also seems to be most relevant to identify as severe complications manifest postoperatively, which is not the case for moderate- and non-MTS patients. ${ }^{3,11}$ 
Table 4 Fluid and Vasopressor Administration

\begin{tabular}{|l|l|l|l|}
\hline & +MTS & Non or Moderate MTS & P-value \\
\hline *Total fluid administration, $\mathrm{mL}$ & $3101 \pm 1180$ & $2681 \pm 686$ & 0.142 \\
**Total fluid loss, $\mathrm{mL}$ & $1537 \pm 1010$ & $1102 \pm 549$ & 0.054 \\
***Fluid balance, $\mathrm{mL}$ & $1564 \pm 537$ & $1579 \pm 596$ & 0.093 \\
Phenylephrine, $\mathrm{mg} / \mathrm{min}$ & $0.016(0.003-0.018)$ & $0.005(0.000-0.013)$ & 0.029 \\
Phenylephrine, infusion min & $190(0-263)$ & $155(10-240)$ & 0.808 \\
Phenylephrine boli, mg & $0.50(0.30-0.60)$ & $0.45(0.20-0.88)$ & 0.946 \\
Ephedrine boli, mg & $20 \pm 16$ & $18 \pm 12$ & 0.691 \\
Number of boli administered after induction of anesthesia & $2(I-4)$ & $2(1-3)$ & 0.254 \\
\hline
\end{tabular}

Notes: Values are means \pm SD. *Includes medicine, crystalloid, blood products, and human albumin. **Includes blood loss and urine output. ***Fluid administration - fluid output.

Abbreviations: EA and LA, early and late activated thoracic epidural anesthesia; +MTS, mesenteric traction syndrome.

Table 5 Perioperative Changes in Plasma Interleukin-6

\begin{tabular}{|l|l|l|l|}
\hline & Baseline & End of Surgery & I8 h Postoperatively \\
\hline $\begin{array}{l}\text { Non or moderate MTS } \\
\text { +MTS }\end{array}$ & $1(I-3)$ & $108(46-204)$ & $61(33-83)$ \\
$95(34-113)$
\end{tabular}

Notes: Values are medians (IQR). ${ }^{*} \mathrm{p}<0.05$, different between groups.

Abbreviations: EA and LA, early and late activated thoracic epidural anesthesia, respectively; +MTS, mesenteric traction syndrome; -MTS, non or moderate mesenteric traction syndrome.

\section{Conclusion}

The incidence of MTS is not prevented by TEA in patients undergoing open esophagectomy. On the contrary, the risk of hypotension is increased in patients exposed to TEA during surgery. Thus, the results suggest that it is advantageous to delay the activation of TEA to the end of the operation. Also, MTS is associated with increased IL-6 and C-reactive protein suggesting a link to a systemic inflammatory response, maybe explaining the aggravated post-operative outcome.

\section{Data Sharing Statement}

The data are available from the corresponding author.

\section{Ethics Approval and Informed Consent}

The study was registered at the European Medicines Agency (EudraCT 2014-002036-14) as approved by the Scientific Ethical Committee, The Capital Region, Denmark (H-2-2013-101 approved by 14th July 2014) and the Danish Health and Medicines Authority (No. 2014060551 approved by 8th August 2014), and was monitored by the Good Clinical Practice unit at Copenhagen University Hospital (No. 2014-4661).

\section{Acknowledgments}

We thank the staff at the operating theatre for their support during the study.

\section{Funding}

This research did not receive any specific grant from funding agencies in the public, commercial, or not-forprofit sectors.

\section{Disclosure}

The authors report no conflicts of interest in this work.

\section{References}

1. Takahashi H, Shida D, Tagawa K, Suzuki T. Hemodynamics of mesenteric traction syndrome measured by FloTrac sensor. J Clin Anesth. 2016;30:46-50. doi:10.1016/j.jclinane.2015.12.001

2. Fujimoto Y, Nomura Y, Hirakawa K, et al. Flurbiprofen axetil provides a prophylactic benefit against mesenteric traction syndrome associated with remifentanil infusion during laparotomy. J Anesth. 2012;26 (4):490-495. doi:10.1007/s00540-012-1368-8

3. Ambrus R, Svendsen LB, Secher NH, et al. Severe postoperative complications may be related to mesenteric traction syndrome during open Esophagectomy. Scand J Surg. 2017;106(3):241-248. doi: $10.1177 / 1457496916683098$

4. Nomura Y, Funai Y, Fujimoto Y, et al. Remifentanil increases the incidence of mesenteric traction syndrome: preliminary randomized controlled trial. J Anesth. 2010;24(5):669-674. doi:10.1007/s00540010-0998-y 
5. Brinkmann A, Seeling W, Wolf CF, et al. Vasopressor hormone response following mesenteric traction during major abdominal surgery. Acta Anaesthesiol Scand. 1998;42(8):948-956. doi:10.1111/ j.1399-6576.1998.tb05355.x

6. Brinkmann A, Seeling W, Rockemann M, et al. Changes in gastric intramucosal $\mathrm{pH}$ following mesenteric traction in patients undergoing pancreas surgery. Dig Surg. 1999;16(2):117-124. doi:10.1159/ 000018703

7. Takahashi H, Shida D, Tagawa K, et al. Therapeutic effects of flurbiprofen axetil on mesenteric traction syndrome: randomized clinical trial. BMC Surg. 2017;17(1):90. doi:10.1186/s12893-0170286-y

8. Greek CR Jr, Couper NB. Prolonged hypotension secondary to mesenteric traction during a transabdominal approach to a thoracoabdominal aneurysm. J Cardiothorac Anesth. 1989;3 (3):341-343. doi:10.1016/0888-6296(89)90119-1

9. Woehlck HJ, Gollapudy S, Roberts CJ, et al. Persistent hypotension and cerebral swelling resulting from mesenteric traction syndrome after omental-to-pial pedicle flap transfer in a young woman with refractory moyamoya disease: a case report. A a Case Rep. 2017;9 (6):169-171. doi:10.1213/XAA.0000000000000557

10. Woehlck H, Antapli M, Mann A. Treatment of refractory mesenteric traction syndrome without cyclooxygenase inhibitors. J Clin Anesth. 2004;16(7):542-544. doi:10.1016/j.jclinane.2003.12.013

11. Olsen AA, Strandby RB, Nerup N, et al. Development of a severe mesenteric traction syndrome during major abdominal surgery is associated with increased postoperative morbidity: secondary data analysis on prospective cohorts. Langenbecks Arch Surg. 2020;405 (1):81-90. doi:10.1007/s00423-019-01847-1

12. Walsh M, Devereaux PJ, Garg AX, et al. Relationship between intraoperative mean arterial pressure and clinical outcomes after noncardiac surgery: toward an empirical definition of hypotension. Anesthesiology. 2013;119(3):507-515. doi:10.1097/ALN.0b01 3e $3182 \mathrm{a} 10 \mathrm{e} 26$

13. van Waes JA, van Klei WA, Wijeysundera DN, et al. Association between intraoperative hypotension and myocardial injury after vascular surgery. Anesthesiology. 2016;124(1):35-44. doi:10.1097/ ALN.0000000000000922

14. Brinkmann A, Wolf CF, Berger D, et al. Perioperative endotoxemia and bacterial translocation during major abdominal surgery: evidence for the protective effect of endogenous prostacyclin? Crit Care Med. 1996;24(8):1293-1301. doi:10.1097/00003246-199608000-00005

15. Rettig TC, Verwijmeren L, Dijkstra IM, et al. Postoperative interleukin-6 level and early detection of complications after elective major abdominal surgery. Ann Surg. 2016;263(6):1207-1212. doi:10.1097/SLA.0000000000001342

16. Ferrer R, Moreno JJ. Role of eicosanoids on intestinal epithelial homeostasis. Biochem Pharmacol. 2010;80(4):431-438. doi:10.1016/j.bcp.2010.04.033

17. Reed MK, Taylor B, Myers SI. The effect of hypoxia on rat splanchnic prostanoid output. Prostaglandins. 1989;38(5):599-608. doi:10.1016/0090-6980(89)90152-4

18. Reed M, Taylor B, Myers SI. The effect of hypoxia on angiotensin-stimulated release of PGI2 from the splanchnic bed. J Trauma. 1990;30(8):993-998. doi:10.1097/00005373-19900800000008

19. Myers SI, Hernandez R. Exaggerated splanchnic PGI2 release following acute hemorrhage is due to new protein synthesis. Prostaglandins Leukot Essent Fatty Acids. 1993;48(3):207-210. doi:10.1016/0952-3278(93)90087-D

20. Myers SI, Evans CT, Hernandez R, Bartula L. Increased splanchnic prostacyclin synthase and cyclooxygenase content and activity during ischemia is due to new protein synthesis. Surgery. 1994;116 (2):432-438.
21. Myers SI, Parks L, Smith G, Miller TA. Elevated PGI2 and PGE2 production in the rat ileum following mild hypotension. J Trauma. 1988;28(8):1202-1206. doi:10.1097/00005373-198808000-00011

22. Lundberg J, Lundberg D, Norgren L, et al. Intestinal hemodynamics during laparotomy: effects of thoracic epidural anesthesia and dopamine in humans. Anesth Analg. 1990;71(1):9-15. doi:10.1213/ 00000539-199007000-00002

23. Gould TH, Grace K, Thorne G, Thomas M. Effect of thoracic epidural anaesthesia on colonic blood flow. Br J Anaesth. 2002;89 (3):446-451. doi:10.1093/bja/89.3.446

24. Ambrus R, Achiam MP, Secher NH, et al. Evaluation of gastric microcirculation by laser speckle contrast imaging during Esophagectomy. J Am Coll Surg. 2017;225(3):395-402. doi:10.1016/j.jamcollsurg.2017.06.003

25. Reed CE. Technique of Open Ivor Lewis Esophagectomy. Oper Tech Thorac Cardiovasc Surg. 2009;14(3):160-175. doi:10.1053/j. optechstcvs.2009.06.001

26. Ring LL, Strandby RB, Henriksen A, et al. Laser speckle contrast imaging for quantitative assessment of facial flushing during mesenteric traction syndrome in upper gastrointestinal surgery. J Clin Monit Comput. 2019;33(5):903-910. doi:10.1007/s10877-018-0226-0

27. Pensado A, Molins N, Alvarez J. Effects of propofol on mean arterial pressure and systemic vascular resistance during cardiopulmonary bypass. Acta Anaesthesiol Scand. 1993;37(5):498-501. doi:10.1111/ j.1399-6576.1993.tb03754.x

28. Rørdam P, Olesen HL, Sindrup J, Secher NH. Effect of epidural anaesthesia on dorsal pedis arterial diameter and blood flow. Clin Physiol. 1995;15(2):143-149. doi:10.1111/j.1475-097X.1995. tb00438.x

29. Hachenberg T, Holst D, Ebel C, et al. Effect of thoracic epidural anaesthesia on ventilation-perfusion distribution and intrathoracic blood volume before and after induction of general anaesthesia. Acta Anaesthesiol Scand. 1997;41(9):1142-1148. doi:10.1111/ j.1399-6576.1997.tb04856.x

30. Michelet P, Roch A, D'Journo XB, et al. Effect of thoracic epidural analgesia on gastric blood flow after oesophagectomy. Acta Anaesthesiol Scand. 2007;51(5):587-594. doi:10.1111/j.13996576.2007.01290.x

31. Lundin S, Wallin BG, Elam M. Intraneural recording of muscle sympathetic activity during epidural anesthesia in humans. Anesth Analg. 1989;69(6):788-793. doi:10.1213/00000539-19891200000018

32. Zakrison T, Nascimento BA Jr, Tremblay LN, Kiss A, Rizoli SB. Perioperative vasopressors are associated with an increased risk of gastrointestinal anastomotic leakage. World J Surg. 2007;31 (8):1627-1634. doi:10.1007/s00268-007-9113-4

33. Dindo D, Demartines N, Clavien PA. Classification of surgical complications: a new proposal with evaluation in a cohort of 6336 patients and results of a survey. Ann Surg. 2004;240(2):205-213. doi:10.1097/01.sla.0000133083.54934.ae

34. Noseir RK, Ficke DJ, Kundu A, Arain SR, Ebert TJ. Sympathetic and vascular consequences from remifentanil in humans. Anesth Analg. 2003;96(6):1645-1650. doi:10.1213/01.ANE.0000061587.13631.67

35. Watt DG, Horgan PG, McMillan DC. Routine clinical markers of the magnitude of the systemic inflammatory response after elective operation: a systematic review. Surgery. 2015;157(2):362-380. doi:10.1016/j.surg.2014.09.009

36. Szczepanik AM, Scislo L, Scully T, et al. IL-6 serum levels predict postoperative morbidity in gastric cancer patients. Gastric Cancer. 2011;14(3):266-273. doi:10.1007/s10120-011-0039-z

37. Singh PP, Zeng IS, Srinivasa S, et al. Systematic review and meta-analysis of use of serum C-reactive protein levels to predict anastomotic leak after colorectal surgery. Br J Surg. 2014;101 (4):339-346. doi:10.1002/bjs.9354 
38. Munteanu A, Munteanu D, Iancu M, et al. Assessing immunological surgical stress markers in patients undergoing digestive surgery for pancreatic, hepatic and gastric tumors. J Buon. 2018;23(6):1655.

39. Babic B, Tagkalos E, Gockel I, et al. C-reactive protein levels after Esophagectomy are associated with increased surgical trauma and complications. Ann Thorac Surg. 2020;109(5):1574-1583. doi:10.1016/j.athoracsur.2019.12.016

40. Smith SA, Roberts DJ, Lipson ME, Buie WD, MacLean AR. Postoperative nonsteroidal anti-inflammatory drug use and intestinal anastomotic dehiscence: a systematic review and meta-analysis. Dis Colon Rectum. 2016;59(11):1087-1097. doi:10.1097/DCR.0000000 000000666
41. Ofman JJ, MacLean CH, Straus WL, et al. A metaanalysis of severe upper gastrointestinal complications of nonsteroidal antiinflammatory drugs. J Rheumatol. 2002;29(4):804-812.

42. Johansson PI, Mortensen CR, Nielsen T, et al. The effect of intraoperative and 6-h postoperative intravenous administration of low-dose prostacyclin on the endothelium, hemostasis, and hemodynamics in patients undergoing a pancreaticoduodenoctemy: a randomized-controlled pilot study. Eur $J$ Gastroenterol Hepatol. 2017;29(4):400-406. doi:10.1097/MEG.0000000000000800

\section{Publish your work in this journal}

Local and Regional Anesthesia is an international, peer-reviewed, open access journal publishing on the development, pharmacology, delivery and targeting and clinical use of local and regional anesthetics and analgesics. The journal welcomes submitted papers covering original research, basic science, clinical studies, reviews \& evaluations, guidelines, expert opinion and commentary, case reports and extended reports. The manuscript management system is completely online and includes a very quick and fair peer-review system, which is all easy to use. Visit http://www.dovepress.com/testimonials. php to read real quotes from published authors. 